\title{
High serum miR-484 expression is associated with the diagnosis and prognosis of patients with non-small cell lung cancer
}

\author{
ZHENLI ZHUANG ${ }^{1}$, CUILING SUN $^{2}$ and HAITAO GONG ${ }^{3}$ \\ ${ }^{1}$ Department of Thoracic Surgery, Yantai Yuhuangding Hospital; \\ ${ }^{2}$ Nursing Department, Yantai Municipal Office Hospital, Yantai, Shandong 264000; \\ ${ }^{3}$ Department Three of Oncology, Laiyang Central Hospital, Laiyang, Shandong 265200, P.R. China
}

Recieved July 20, 2018; Accepted March 1, 2019

DOI: $10.3892 /$ etm.2019.8010

\begin{abstract}
The aim of the current study was to assess the expression and clinical significance of serum microRNA (miR)-484 in patients with non-small cell lung cancer (NSCLC). Reverse transcription-quantitative polymerase chain reaction was performed to determine the expression of miR-484 in the serum of patients with NSCLC and NSCLC cell lines. Cell counting kit-8, flow cytometry, cell migration and cell invasion assays were performed to assess the role of miR-484 in the malignant changes associated with NSCLC cells. Furthermore, to assess the diagnostic value of miR-484, receiver operating curve (ROC) analysis was performed and the clinical relevance of serum miR-484 expression in patients with NSCLC was determined. A Kaplan-Meier analysis with the log-rank test was performed to assess the overall survival rate patients. To the best of our knowledge, the current study demonstrates for the first time that serum miR-484 was increased in patients with NSCLC compared with healthy controls. Additionally, serum miR-484 was revealed to be positively associated with histological grade, lymph node metastasis, distant metastasis and clinical stage. Patients with NSCLC and high serum miR-484 levels demonstrated significantly poorer overall survival rates compared with those exhibiting lower serum miR-484 expressions. ROC analysis revealed that serum miR-484 could screen patients with NSCLC patients from healthy controls with a high sensitivity and specificity. In vitro analysis also demonstrated that miR-484 was significantly upregulated in NSCLC cell lines, including 95D and H358 cells. Furthermore, the suppression of miR-484 decreased cell proliferation, cell migration and invasion. In summary, the results of the present
\end{abstract}

Correspondence to: Dr Haitao Gong, Department Three of Oncology, Laiyang Central Hospital, 111 Changshan Road, Laiyang, Shandong 265200, P.R. China

E-mail: ag20180312@sina.com

Key words: microRNA-484, non-small cell lung cancer, serum, biomarker, diagnosis, prognosis study demonstrated that increased serum miR-484 expression is associated with the diagnosis and prognosis of patients with NSCLC.

\section{Introduction}

As one of the major malignancies in humans, lung cancer is a leading cause of cancer mortality worldwide (1). It has been reported that the morbidity and mortality of lung cancer has continued to increase in recent years (2). According to pathological characteristics, lung cancer can be divided into non-small cell lung cancer (NSCLC) and small cell lung cancer (3), the former of which accounts for $\sim 75-80 \%$ of all lung cancer cases (4). At present, the most effective therapy for patients with NSCLC is surgery (5). Unfortunately, many patients are diagnosed at an advanced stage, which results in failed surgery (6). Although great advances have been made in surgery, chemotherapy, radiotherapy and targeting therapy, patients with NSCLC still experience limited early prognosis and diagnosis methods, causing substantial financial and psychological burdens (7). At the early onset of the disease, few symptoms are noticed by patients with NSCLC (8). Therefore, it is important to quickly and effectively identify possible biomarkers of NSCLC to develop early preventative therapeutic methods.

MicroRNAs (miRNAs or miRs) are small non-coding RNAs that exert extensive post transcriptional regulation by binding to the 3'untranslated region (3'UTR) of target mRNAs $(9,10)$. The abnormal expression of microRNAs (miRNAs or miRs) have been detected in various types of tumor, including NSCLC $(11,12)$. For example, miR-200c has been demonstrated to suppress NSCLC invasion and metastasis by targeting ubiquitin-specific peptidase 25 (11). In addition, miR-377 suppresses NSCLC by decreasing the expression of astrocyte elevated gene-1 (12). Circulating miRNAs, including those in serum and plasma, have been demonstrated to serve as potential noninvasive biomarkers for the early identification of various types of cancer due to their long-term stability in the circulatory system $(13,14)$. In NSCLC, the upregulation of plasma miR-21 has been demonstrated to be effective for its early detection and chemosensitivity (15). In addition, 
circulating miR-29a and miR-150 have been reported to be associated with the delivery dose of thoracic radiation therapy in NSCLC (16).

The expression pattern of miR-484 has been revealed to be significantly different in various types of tumor, including breast cancer, cervical cancer and NSCLC $(17,18)$. It has been reported that enhanced miR-484 promotes the progression of NSCLC by suppressing apoptotic protease activating factor-1 (19). However, to the best of our knowledge, whether miR-484 could be used as a potential biomarker for the early detection of NSCLC is yet to be elucidated. The aim of the current study was to assess the expression and clinical significance of serum miR-484 in patients with NSCLC.

\section{Patients and methods}

Patients and specimens. A total of 150 serum samples were collected from 150 patients with NSCLC (male, $\mathrm{n}=85$; female, $n=65$; age, 56.8 \pm 13.9 years) at Laiyang Central Hospital (Laiyang, China) from Feb 2016 to Jan 2017. The diagnosis of all samples was histopathologically confirmed by two pathologists at Laiyang Central Hospital. None of the patients had received neoadjuvant chemotherapy or radiotherapy prior to surgery. The clinicopathological results were determined according to the classification of malignant tumors by the World Health Organization (20). TNM was staged (Stage I, $n=45$; Stage II, $n=55$; Stage III, $\mathrm{n}=27$; Stage IV, $\mathrm{n}=28$ ) and the details are provided in Table I. Overall survival was defined as the time interval between the date of surgery and the date of mortality. An additional 50 healthy volunteers (24 males, 26 females; average age, $58.6 \pm 14.5$ years) from the Physical Examination Center of Laiyang Central Hospital between February 2016 and February 2017 were enrolled as the normal control group. Informed consent was obtained from all participants prior to enrollment and the study was approved by the Ethics Committee of Laiyang Central Hospital (Laiyang, China). Peripheral blood was collected in VP-AS109K Vacutainer tubes (Terumo Medical Corporation, Tokyo, Japan) and incubated at room temperature for $30 \mathrm{~min}$. To isolate serum, peripheral blood was centrifuged at $1,500 \times \mathrm{g}$ for $10 \mathrm{~min}$ at $4^{\circ} \mathrm{C}$ to. Serum was then further centrifuged at $20,000 \mathrm{x} \mathrm{g}$ for $10 \mathrm{~min}$ at $4^{\circ} \mathrm{C}$ to remove cell debris. Finally, serum was divided into $200 \mu \mathrm{l}$ aliquots and stored at $-80^{\circ} \mathrm{C}$ until use. Hemolyzed serum samples were excluded.

Cell culture. Four NSCLC cell lines, including A549, NCI-H460, 95D and H358, and a normal human bronchial epithelial cell line (16HBE) were purchased from the Institute of Biochemistry and Cell Biology of the Chinese Academy of Sciences (Shanghai, China). All cells were cultured in RPMI 1640 medium (Invitrogen; Thermo Fisher Scientific, Inc., Waltham, MA, USA) supplemented with $10 \%$ fetal bovine serum (FBS) (Invitrogen; Thermo fisher Scientific, Inc.), $100 \mathrm{U} / \mathrm{ml}$ penicillin and $100 \mu \mathrm{g} / \mathrm{ml}$ streptomycin in a humidified incubator at $37^{\circ} \mathrm{C}$ with $5 \% \mathrm{CO}_{2}$.

Transient transfection. An miR-484 inhibitor (5'-ATGGGAGGGGACTGAGCCTGA-3') or a negative control (NC; 5'-ACUAGUCGAUCUAUGUGUGAUATT-3'; both Shanghai GenePharma Co., Ltd., Shanghai, China) was transfected into 95D and H358 cells using $6 \mu 1$ Lipofectamine ${ }^{\circledR}$ 2000 (Invitrogen; Thermo Fisher Scientific, Inc.) per well in a 6-well plate according to the manufacturers' protocol. $95 \mathrm{D}$ and $\mathrm{H} 358$ cells $\left(1 \times 10^{6}\right.$ cells/well) were seeded in a six-well plate with $2 \mathrm{ml}$ RPMI-1640 medium. After cells reached a $60 \%$ confluence, the miR-484 inhibitor or NC was mixed with Lipofectamine ${ }^{\circledR} 2000$ at room temperature for $20 \mathrm{~min}$. Then, the mixture was added into each well at a final concentration of $20 \mathrm{nM}$ for $48 \mathrm{~h}$ and the cells were collected for further analysis.

RNA extraction. To isolate the RNA $(10 \mu \mathrm{g})$ from the serum samples $(5 \mathrm{ml})$ or NSCLC cancer tissues or 95D and H358 cells transfected with miR-484 inhibitor for 1, 2, 3, 4 and 5 days, RNAVzol LS (Vigorous Biotechnology Co., Ltd., Beijing, China) was used in the present study according to the manufacturer's protocol. To determine the concentration and purity of the RNA samples, the $\mathrm{OD}_{260} / \mathrm{OD}_{280}$ ratio was evaluated using a microplate reader (Model 3550; Thermo Fisher Scientific, Inc.).

Reverse transcription-quantitative polymerase chain reaction (RT-qPCR). For RT, a total of $1 \mu \mathrm{g}$ of RNA isolated from the serum samples $(5 \mathrm{ml})$ or NSCLC cancer tissues or 95D and H358 cells was added to a TaqMan MicroRNA Reverse Transcription kit (Applied Biosystems; Thermo Fisher Scientific, Inc.). U6, a small nuclear RNA, was used as an internal control (21). The primer sequences for reverse transcription were as follows: miR-484, 5'-CGTATCCAG TGCAGGGTCCGAGGTATTCGCACTGGATACGACATC GG-3'; and U6, 5'-TCGTATCCAGTGCAGGGTCCGAGG TATTCGCACTGGATACGACAAATATG-3'. The primer sequences for qPCR were as follows: miR-484 forward, 5'-TCAGGCTCAGTCCCCTC-3'; U6, forward 5'-GCGTCG TGAAGCGTTC-3'; and universal reverse primer, 5'-GTG CAGGGTCCGAGGT-3'.

PCR amplifications were performed using a $10 \mu \mathrm{l}$ reaction system, which contained $5 \mu \mathrm{l} \mathrm{SYBR} \mathrm{Green} \mathrm{Supermix} \mathrm{(Bio-Rad}$ Laboratories, Inc., Hercules, CA, USA), $0.4 \mu$ l forward primer, $0.4 \mu \mathrm{l}$ reverse primer, $2.2 \mu \mathrm{l}$ double-distilled water and $2 \mu \mathrm{l}$ template cDNA using a Bio-Rad iCycler iQ Real-Time PCR Detection System (Bio-Rad Laboratories, Inc.). The thermocycling conditions for qPCR was listed as follows: Denaturation at $95^{\circ} \mathrm{C}$ for $10 \mathrm{~min}$, followed by 40 cycles of annealing and elongation at $95^{\circ} \mathrm{C}$ for $15 \mathrm{sec}$ and a final extension at $60^{\circ} \mathrm{C}$ for $1 \mathrm{~min}$. Relative levels of $\mathrm{miR}-484$ were determined using the $2^{-\Delta \Delta \mathrm{Cq}}$ method (22). In the present study, the cut off value was defined as the mean value of serum miR-484 level in patients with NSCLC, that was divided into high serum miR-484 $(>16.06)$ and low miR-484 ( $\leq 16.06)$ levels.

Cell proliferation assay. To determine cell proliferation, a Cell Counting kit-8 (CCK-8; Beijing Solarbio Science \& Technology Co., Ltd., Beijing, China) was used. 95D and H358 cells were seeded into 96-well plates at a density of 2,000 cells/well. Subsequently, 95D and H358 cells were transfected with a miR-484 inhibitor or an NC for 1,2,3, 4 and 5 days as aforementioned. For the cell proliferation assay, $10 \mu \mathrm{l}$ of CCK- 8 solution was added into each well following 1, 2, 3, 4 and 5 days of 
Table I. Association of microRNA-484 expression and the clinicopathological variables of patients with non-small cell lung cancer.

\begin{tabular}{|c|c|c|c|c|}
\hline Variables & Number & Low $(n=68)$ & $\operatorname{High}(\mathrm{n}=82)$ & P-value \\
\hline Age & & & & 0.825 \\
\hline$<60$ & 70 & 34 & 36 & \\
\hline$\geq 60$ & 80 & 39 & 41 & \\
\hline Sex & & & & 0.532 \\
\hline Male & 85 & 43 & 42 & \\
\hline Female & 65 & 32 & 33 & \\
\hline Tumor size & & & & 0.278 \\
\hline$<5 \mathrm{~cm}$ & 100 & 53 & 47 & \\
\hline$\geq 5 \mathrm{~cm}$ & 50 & 24 & 26 & \\
\hline Histological grade & & & & 0.013 \\
\hline I & 98 & 47 & 51 & \\
\hline II-III & 52 & 25 & 27 & \\
\hline Lymph node metastasis & & & & 0.004 \\
\hline Yes & 50 & 24 & 26 & \\
\hline No & 100 & 53 & 47 & \\
\hline Distant metastasis & & & & 0.032 \\
\hline Yes & 52 & 23 & 32 & \\
\hline No & 98 & 45 & 53 & \\
\hline Clinical stage & & & & 0.004 \\
\hline I-II & 95 & 55 & 40 & \\
\hline III-IV & 55 & 32 & 23 & \\
\hline
\end{tabular}

Clinical stage, Tumor node, metastasis staging.
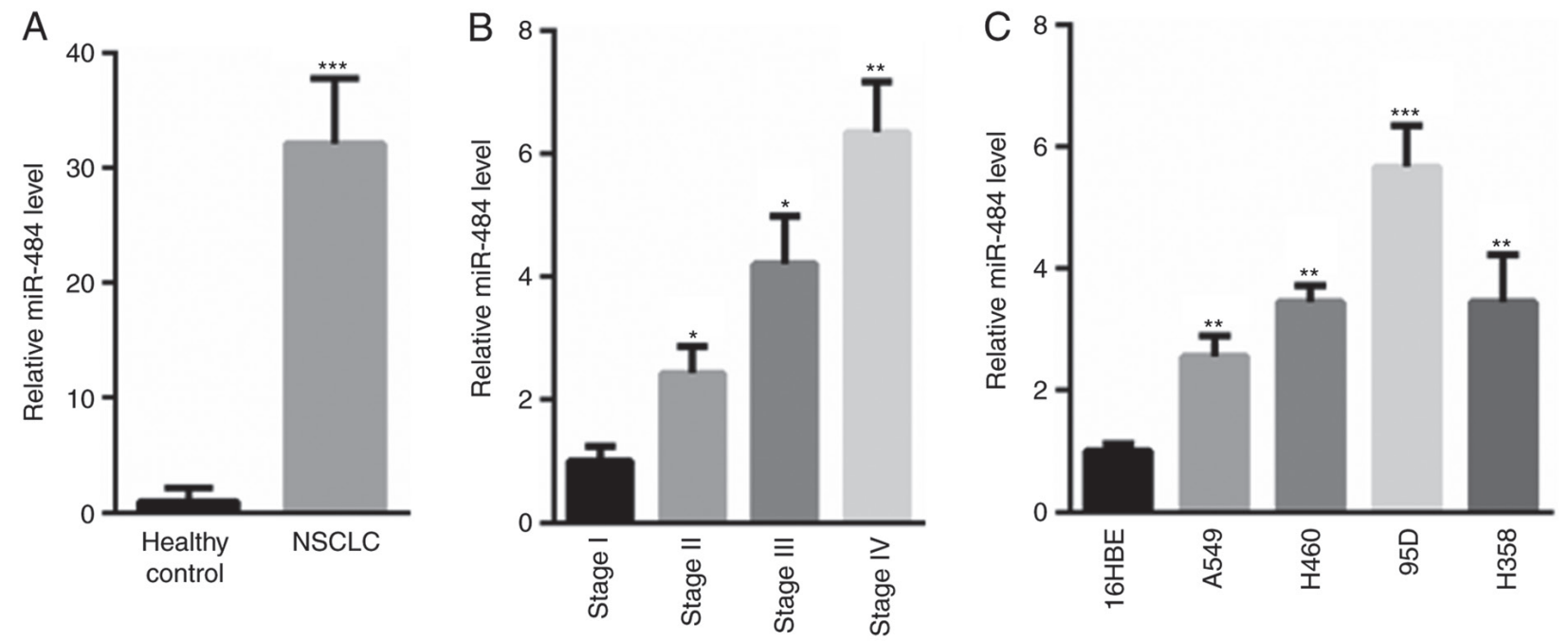

Figure 1. Increased miR-484 levels in patient serum and NSCLC cell lines. (A) serum miR-484 levels were assessed in patients with NSCLC (n=150) and healthy controls $(\mathrm{n}=50)$. (B) miR-484 levels were assessed in patients with NSCLC ( $\mathrm{n}=150)$ according to tumor node metastasis staging (Stage I, $\mathrm{n}=45$; Stage II, $\mathrm{n}=55$; Stage III, $\mathrm{n}=27$; Stage IV, $\mathrm{n}=28$ ) and in (C) various cell lines. ${ }^{*} \mathrm{P}<0.05,{ }^{* * *} \mathrm{P}<0.01$ and ${ }^{* * * *} \mathrm{P}<0.001$ vs. healthy controls, stage I or $16 \mathrm{HBE}$. miR, microRNA; NSCLC, non-small cell lung cancer.

incubation at $37^{\circ} \mathrm{C}$ for $15 \mathrm{~min}$. WST-8 was metabolized in viable cells and produced a chromogen that was detected at $450 \mathrm{~nm}$ using a Spectra Max M2 spectrophotometer (SpectraMax M2, Molecular Devices, LLC, Sunnyvale, CA, USA).
Cell cycle analysis. For cell cycle analysis, 95D and H358 cells were transfected with a miR-484 inhibitor or an NC for $48 \mathrm{~h}$ and then harvested. Subsequently, cells were fixed with $70 \%$ ethanol at $-20^{\circ} \mathrm{C}$ for $24 \mathrm{~h}$. Then, 95D and $\mathrm{H} 358$ 
$\left(\sim 1 \times 10^{6}\right)$ cells were trypsinized, washed twice with PBS and fixed in $70 \%$ ice-cold ethanol for $1 \mathrm{~h}$. To remove ethanol and displace sediment, samples were centrifuged at $300 \mathrm{x}$ g for $5 \mathrm{~min}$ at $4^{\circ} \mathrm{C}$ and were then exposed to $100 \mathrm{mg} / \mathrm{ml} \mathrm{RNaseA}$ (Sigma-Aldrich; Merck KGaA, Darmstadt, Germany) for $30 \mathrm{~min}$ at $37^{\circ} \mathrm{C}$. Propidium iodide (Nanjing KeyGen Biotech Co., Ltd., Nanjing, China) was used to stain cellular DNA at room temperature for $10 \mathrm{~min}$. Cell-cycle distributions were assessed using a BD FACSCalibur flow cytometry system (BD Biosciences, Franklin Lakes, NJ, USA) with ModFit software version 4.1 (Verity Software House, Inc., Topsham, ME, USA).

Cell migration and invasion assays. Cell migration assays were performed with Boyden chambers (8- $\mu \mathrm{m}$ pore filter; Corning Inc., Corning, NY, USA). For the cell invasion assay, filter surfaces were precoated with $1 \%$ Matrigel (BD Biosciences). 95D and H358 cells were seeded in six-well plates at a density of $10^{5}$ cells/well in the upper chamber with RPMI-1640 medium. 95D and H358 cells were also transfected with a miR-484 inhibitor or an $\mathrm{NC}$ for $48 \mathrm{~h}$ in the corresponding upper chamber. RPMI-1640 medium $(600 \mu \mathrm{l})$ with $20 \%$ FBS was plated in the lower chamber. Following incubation at $37^{\circ} \mathrm{C}$ for $48 \mathrm{~h}$, cotton swabs were used to remove non-migratory and non-invading cells. Migratory and invasive cells were then fixed in methanol for $30 \mathrm{~min}$ at $37^{\circ} \mathrm{C}$ and stained with $0.5 \%$ crystal violet for $1 \mathrm{~h}$ at $37^{\circ} \mathrm{C}$. Stained cells were counted in 5 random fields under a light microscope (magnification, x40; XDS-500D; Shanghai Caikon Optical Instrument Co., Ltd., Shanghai, China).

Statistical analysis. Data were analyzed using SPSS software (version 13.0; SPSS, Inc., Chicago, IL, USA). The relevant data were expressed as the mean \pm standard deviation. To examine differences between two groups, a two-tailed unpaired Student's t-test was used. For comparisons of more than two groups, one-way analysis of variance followed by a Tukey's post hoc test were performed. The $\chi^{2}$-test was used to assess the association between serum miR-484 expression and clinicopathologic features of NSCLC. A receiver operating characteristic curve (ROC) curve was created and the area under the curve was determined to assess the specificity and sensitivity of circulating miR-484 as a diagnostic biomarker. A Cox proportional hazards model was used for multivariate analysis. Multivariable Cox regression models were built for the analysis of risk factors for survival outcomes between patients with NSCLC and healthy controls. The comparison of overall survival rate between patients with NSCLC and healthy controls was made using the Kaplan-Meier method with a log-rank test. $\mathrm{P}<0.05$ was considered to indicate a statistically significant difference.

\section{Results}

Serum miR-484 is increased in the patients with NSCLC and NSCLC cell lines. The current study assessed levels of miR-484 in the serum of patients with NSCLC and healthy controls. Compared with the serum miR-484 levels of the healthy controls $(1 \pm 1.23)$, miR-484 was significantly higher in patients with NSCLC (32.12 \pm 5.67 ; Fig. 1A). The level of miR-484 was then assessed according to TNM staging. Compared with stage I $(1 \pm 0.24)$, the level of miR-484 was increased in stage II $(2.43 \pm 0.43)$, stage III $(4.21 \pm 0.78)$ and stage IV $(6.35 \pm 0.82$;

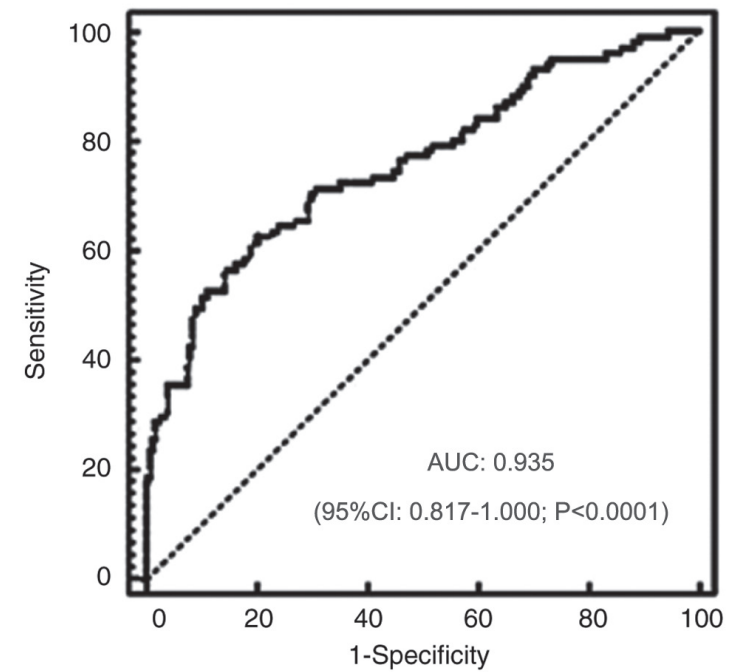

Figure 2. Receiving operating characteristic analysis of serum miR-484 in patients with non-small cell lung cancer $(n=150)$ and healthy controls $(n=50)$.

Fig. 1B). In addition, relative miR-484 levels were assessed in various NSCLC cell lines. Compared with the level of miR-484 in the 16HBE cells $(1 \pm 0.12)$, the level of miR- 484 was significantly higher in A549 (2.56 \pm 0.34$), \mathrm{H} 460$ (3.45 \pm 0.27$), 95 \mathrm{D}$

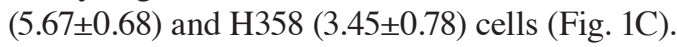

Serum miR-484 distinguishes patients with NSCLC from healthy controls. The diagnostic value of serum miR-484 in patients with NSCLC was determined. ROC analysis revealed that serum miR-484 could distinguish patients with NSCLC from healthy controls, with an ROC curve area of 0.935 (95\% confidence interval: 0.817-1.000; $\mathrm{P}<0.0001$; Fig. 2).

Association of Serum miR-484 with the clinicopathological characteristics of patients with NSCLC. The current study analyzed the clinical relevance of serum miR-484 expression in patients with NSCLC. Patients with NSCLC $(n=150)$ were further divided into two groups based on their average expression of serum miR-484: A high expression group $(n=82)$ and a low expression group $(\mathrm{n}=68)$. As presented in Table $\mathrm{I}$, serum miR-484 was positively associated with histological grade, lymph node metastasis, distant metastasis and clinical stage. However, no association was identified between serum miR-484 and patient sex, age, or tumor size.

miR-484 inhibition suppresses NSCLC cell proliferation and induces cell cycle arrest. To inhibit miR-484 levels, 95D and $\mathrm{H} 358$ cells were transfected with a miR-484 inhibitor or an NC for 1, 2, 3, 4 and 5 days. As presented in Fig. 3A, transfection with the miR-484 inhibitor significantly suppressed miR-484 levels in 95D and H358 cells at each day of incubation when compared with $\mathrm{NC}$ treated cells. The results also revealed the reduced growth of 95D and $\mathrm{H} 358$ cells transfected with the miR-484 inhibitor compared with those transfected with the NC (Fig. 3B). Flow cytometric analysis determined that the inhibition of miR-484 induced a more pronounced cell cycle arrest in 95D and H358 cells compared with the NC group (Fig. 3C). These data indicate the tumor suppressive role of the miR-484 inhibitor in NSCLC cells. 

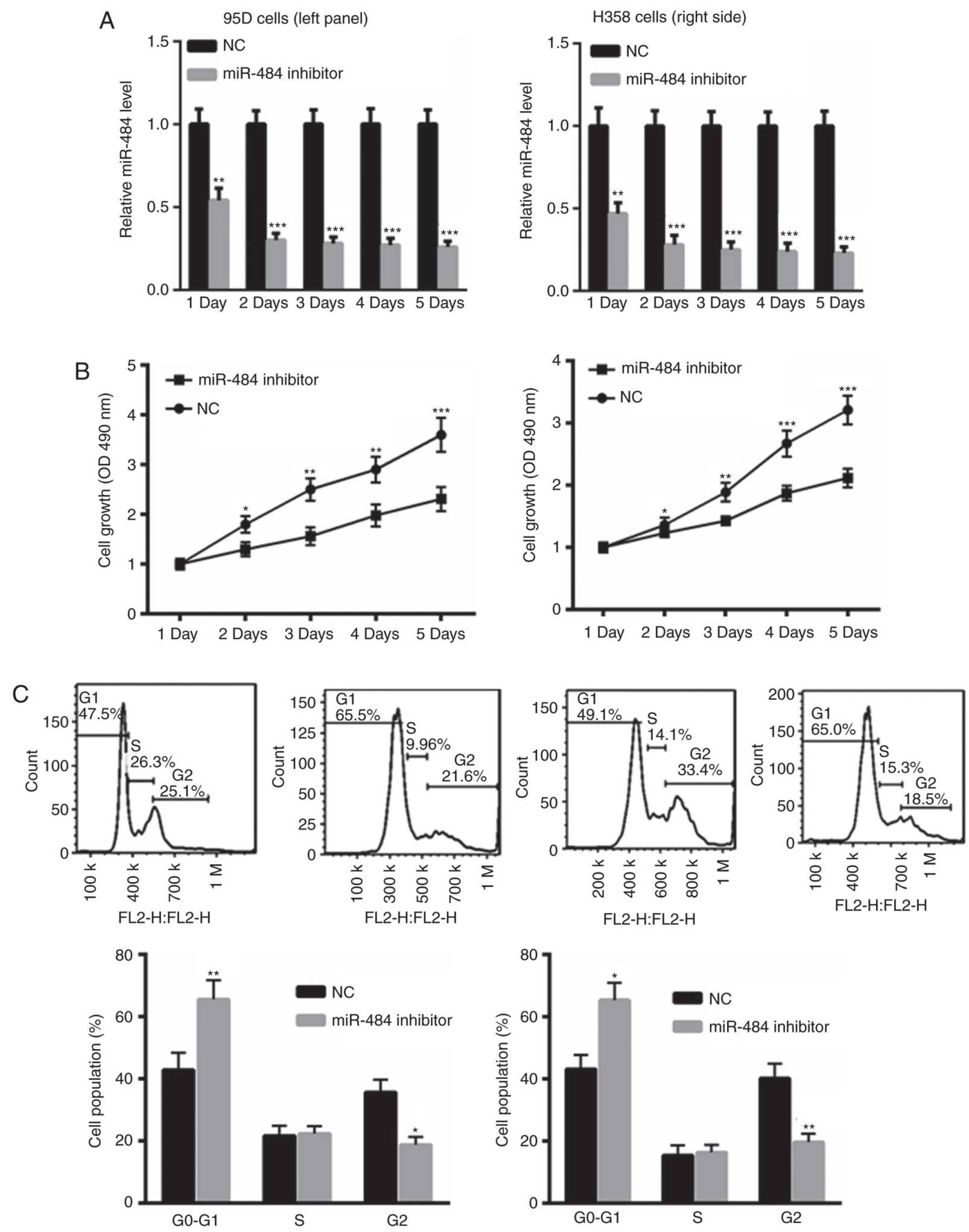

Figure 3. miR-484 inhibition suppresses non-small cell lung cancer cell proliferation and induces cell cycle arrest. (A) Reverse transcription-quantitative polymerase chain reaction analysis was performed to assess miR-484 levels in $95 \mathrm{D}$ and $\mathrm{H} 358$ cells for 1,2,3,4 and 5 days ( $\mathrm{n}=3$ independent experiments). A cell counting kit-8 assay and flow cytometry was performed to assess (B) cell proliferation and (C) the cell cycle, respectively. ( $\mathrm{n}=3$ independent experiments). ${ }^{*} \mathrm{P}<0.05,{ }^{* *} \mathrm{P}<0.01$ and ${ }^{* * *} \mathrm{P}<0.001$ vs. NC. miR, microRNA; NC, negative control.

miR-484 inhibition reduces NSCLC cell invasion and migration. The migration and invasion of 95D and H358 cells transfected with miR-484 were decreased compared with those transfected with the NC (Fig. 4A and B). The results indicate the oncogenic role of miR-484 in the development of NSCLC.
miR-484 upregulation predicts the deterioration of NSCLC. The present study compared the overall survival rate of patients with NSCLC and high or and low serum miR-484 levels. The cut off value was defined as the mean value of serum miR-484 in patients with NSCLC (high serum miR-484, >16.06; low 
A

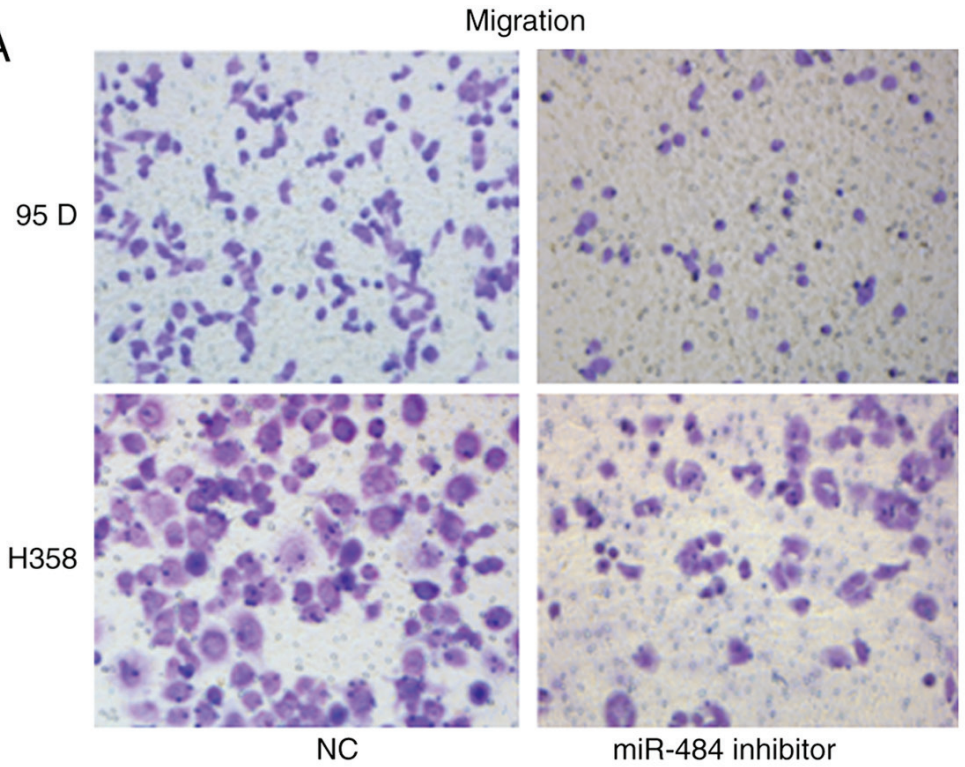

B

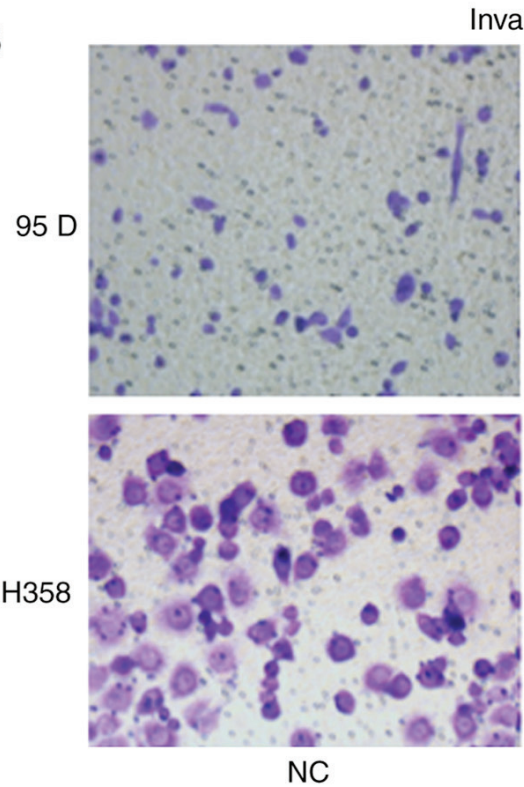

Invasion
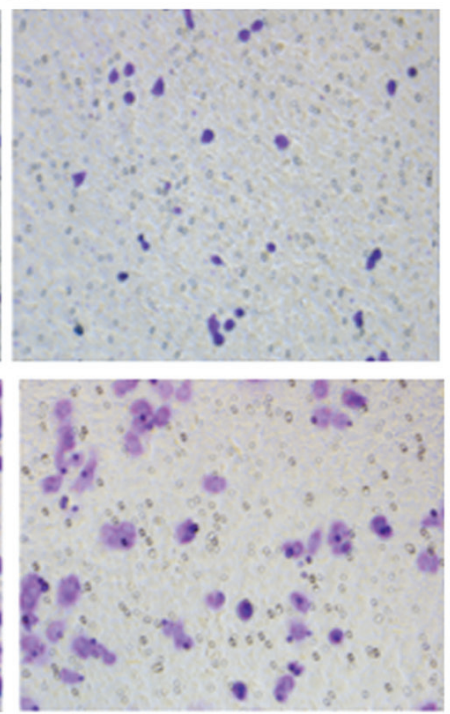

miR-484 inhibitor
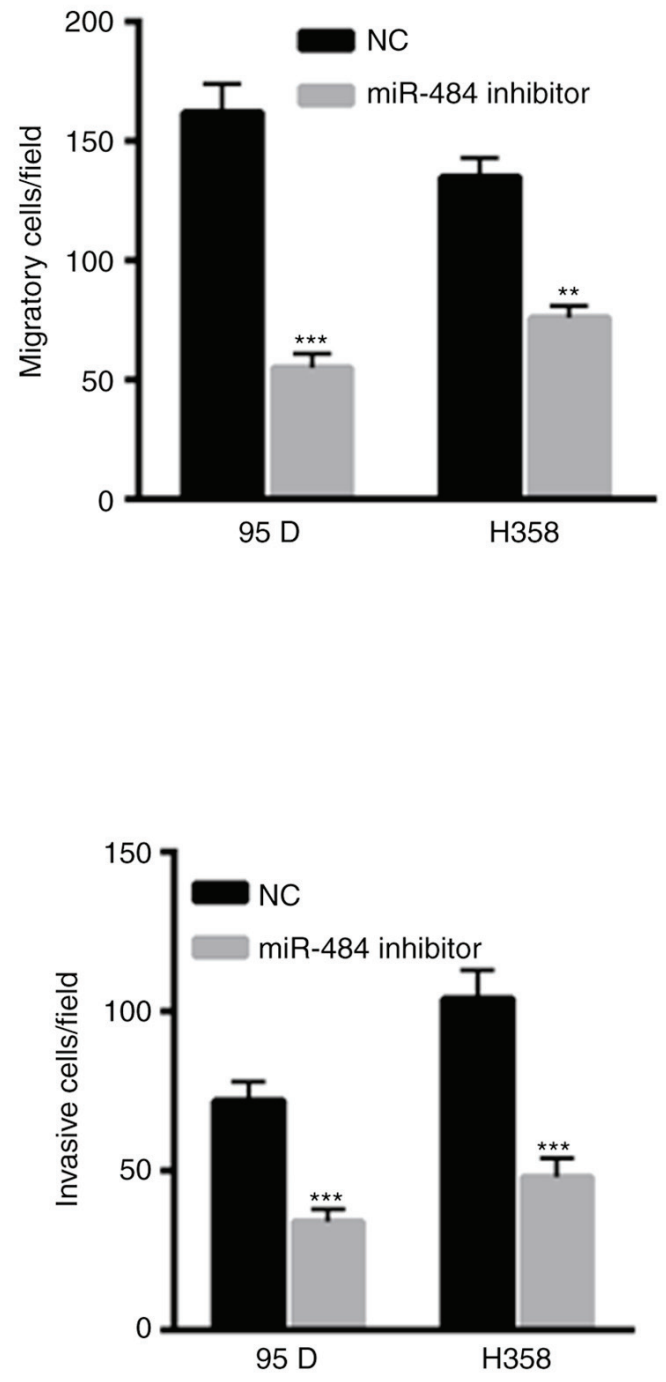

Figure 4. Effect of miR-484 inhibition on non-small cell lung cancer cell (A) invasion and (B) migration (original magnification, $x 40)$ ( $n=3$ independent experiments). ${ }^{* *} \mathrm{P}<0.01$ and ${ }^{* * *} \mathrm{P}<0.001$ vs. the NC. miR, microRNA; NC, negative control.

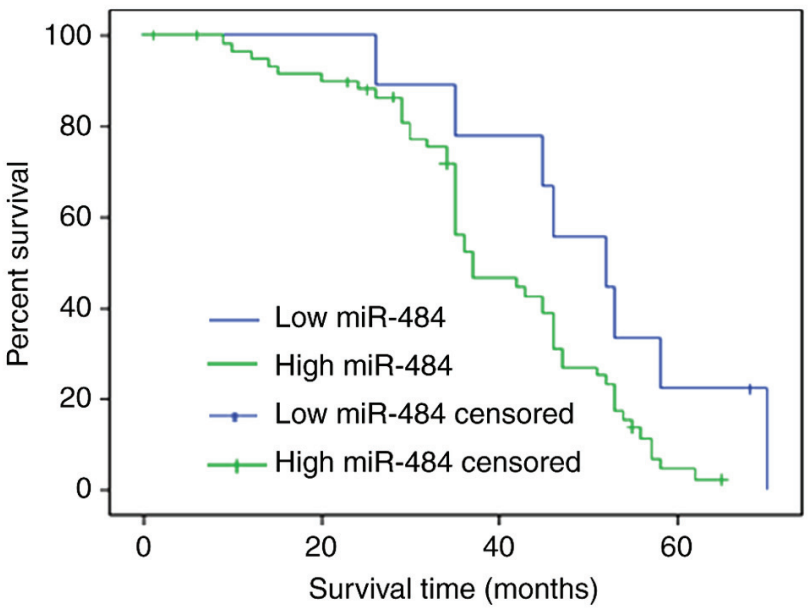

Figure 5. Overall survival rates of non-small cell lung cancer patients with low serum miR-484 $(n=87)$ and high serum miR-484 $(n=63)$.
miR-484, $\leq 16.06)$. Compared with low serum miR-484 patients, high serum miR-484 NSCLC patients exhibited a shorter overall survival time (Fig. 5). Univariate and multivariate analysis was performed to assess whether serum miR-484 was an independent prognostic parameter. According to univariate analysis, the following were significant risk factors for poor survival: Lymph node metastasis, distant metastasis, clinical stage and serum miR-484 (Table II). According to multivariate analysis with Cox regression, lymph node metastasis, distant metastasis, clinical stage and serum miR-484 were independent prognostic factors for NSCLC (Table II).

\section{Discussion}

NSCLC is one of the mostcommon malignancies that threatens human health and life (23). The major therapy methods for NSCLC include radiotherapy and chemotherapy (24), but 
Table II. Univariate and multivariate analysis of overall survival in patients with non-small cell lung cancer

\begin{tabular}{|c|c|c|c|c|}
\hline \multirow[b]{2}{*}{ Variables } & \multicolumn{2}{|c|}{ Univariate analysis } & \multicolumn{2}{|c|}{ Multivariate analysis } \\
\hline & HR & P-value & HR & P-value \\
\hline Age & 1.534 & 0.421 & - & - \\
\hline Sex & 1.321 & 0.578 & - & - \\
\hline Tumor size & 1.678 & 0.113 & - & - \\
\hline Histology type & 1.345 & 0.203 & - & - \\
\hline Lymph node metastasis & 3.932 & 0.012 & 3.245 & 0.024 \\
\hline Distant metastasis & 3.012 & 0.015 & 2.543 & 0.036 \\
\hline Clinical stage & 3.934 & 0.006 & 3.465 & 0.009 \\
\hline Serum miR-484 & 3.865 & 0.003 & 3.452 & 0.001 \\
\hline
\end{tabular}

HR, hazard ratio; miR, microRNA.

due to resistance, the mortality rate of NSCLC remains high (25). Furthermore, the underlying mechanism by which NSCLC is modulated is not fully understood (25). miRNAs are key regulators of NSCLC progression and therefore may become an important therapeutic target (26). The abnormal expression of circulating miRNA has also been widely reported in patients with NSCLC $(6,26)$.

Increasing evidence has indicate the important role of miR-484 in various types of tumor $(18,27,28)$. For instance, increased miR-484 levels have been revealed to promote glioma progression by regulating extracellular signal-regulated kinase $1 / 2$ signaling (27). In metastatic renal cell carcinoma, miR-484 has been reported to be increased and associated with tumor progression (28). However, in cervical cancer, miR-484 serves as a tumor suppressor by suppressing zinc finger E-box-binding homeobox 1 and SMAD2 (18). Circulating miRNA exhibits a good stability in serum, which is associated with the occurrence and development of tumors (29). In addition, serum samples are easy to obtain and as such may be used for the early screening of tumors in healthy individuals (29). Chen et al (30) reported 10 differentially expressed miRNAs in the serum of patients with NSCLC patients, including miR-20a, miR-24, miR-145, miR-152, miR-199a-5p, miR-221, miR-222, miR-223 and miR-320. The authors concluded that these may serve as potential biomarkers for patients with NSCLC. However, to the best of our knowledge, whether serum miR-484 is differentially expressed in patients with NSCLC is yet to be elucidated, despite the fact that a high miR-484 expression has been reported in NSCLC tissue samples and cell lines (19).

To the best of our knowledge, the current study demonstrated for the first time that serum miR-484 is increased in patients with NSCLC compared with healthy controls. The clinical relevance of serum miR-484 expression was also assessed in patients with NSCLC. The results revealed that serum miR-484 was positively associated with histological grade, lymph node metastasis, distant metastasis and clinical stage. These data indicated that higher miR-484 levels are associated with the severity of malignancy in patients with NSCLC. Furthermore, based on the results of ROC analysis, the data revealed that serum miR-484 could differentiate patients with NSCLC from healthy controls, indicating that serum miR-484 may serve as a potential non-invasive biomarker for NSCLC.

The present study also analyzed the prognostic significance of serum miR-484 in patients with NSCLC. A Kaplan-Meier analysis with a log-rank test demonstrated that patients with NSCLC and a high serum expression of miR-484 demonstrated significantly poorer overall survival rates than those with low serum miR-484 levels. Additionally, according to the multivariate Cox proportional hazards analysis, high serum miR-484 expression was independently associated with poor survival. The current study therefore hypothesizes that serum miR-484 may be used as an effective biomarker for the diagnosis and prognosis of patients with NSCLC.

The present study has various limitations. Only a limited number of samples were included in the current study and an increased sample size should be used in the future to validate the accuracy of miR-484 as a biomarker. Furthermore, more experiments should be performed to confirm that miR-484 may be utilized to screen patients with lung cancer from healthy individuals. For instance, ROC analysis should be performed to analyze the association between serum miR-484 and the TNM stage of patients, which would validate whether miR-484 could be used as an early biomarker for NSCLC.

In summary, the present study demonstrated that miRNA-484 was upregulated in the serum of patients with NSCLC. Increased miRNA-484 expression was also positively associated with aggressive progression and poor prognosis. These results demonstrate that serum miRNA-484 may be used as a potential biomarker for patients with NSCLC.

\section{Acknowledgements}

Not applicable.

\section{Funding}

The present study was supported by funding obtained from Laiyang Central Hospital (Laiyang, China; grant no. LYCH-20180634). 


\section{Availability of data and materials}

The datasets used and/or analyzed during the present study are available from the corresponding author on reasonable request.

\section{Authors' contributions}

ZZ performed the experiments and analyzed the data. CS performed RT-qPCR experiments. HG designed the experiments, analyzed the data and gave approval for the publication of the final version of the manuscript. All authors read and approved the final manuscript.

\section{Ethics approval and consent to participate}

The present study was approved by the Research Ethics Committee of Laiyang Central Hospital (Laiyang, China) and all patients provided written informed consent prior to enrollment.

\section{Patient consent for publication}

Not applicable.

\section{Competing interests}

The authors declare that they have no competing interests.

\section{References}

1. Tian W, Wang G, Liu Y, Huang Z, Zhang C, Ning K, Yu C, Shen Y, Wang M, Li Y, et al: The miR-599 promotes non-small cell lung cancer cell invasion via SATB2. Biochem Biophys Res Commun 485: 35-40, 2017.

2. Wang D, Ma J, Ji X, Xu F and Wei Y: miR-141 regulation of EIF4E expression affects docetaxel chemoresistance of non-small cell lung cancer. Oncol Rep 37: 608-616, 2017.

3. Wang H, Shen Q, Zhang X, Yang C, Cui S, Sun Y, Wang L, Fan X and Xu S: The long non-coding RNA XIST controls non-small cell lung cancer proliferation and invasion by modulating miR-186-5p. Cell Physiol Biochem 41: 2221-2229, 2017.

4. Wang J, Wang Y, Sun D, Bu J, Ren F, Liu B, Zhang S, Xu Z, Pang $S$ and $X u$ S: miR-455-5p promotes cell growth and invasion by targeting $\mathrm{SOCO} 3$ in non-small cell lung cancer. Oncotarget 8 : 114956-114965, 2017.

5. Wang K, Dong L, Fang Q, Xia H and Hou X: Low serum miR-98 as an unfavorable prognostic biomarker in patients with non-small cell lung cancer. Cancer Biomark 20: 283-288, 2017.

6. Wang L, Liu W, Zhang YP and Huang XR: The miR-224 promotes non-small cell lung cancer cell proliferation by directly targeting RASSF8. Eur Rev Med Pharmacol Sci 21: 3223-3231, 2017.

7. Wang M, Meng B, Liu Y, Yu J, Chen Q and Liu Y: MiR-124 inhibits growth and enhances radiation-induced apoptosis in non-small cell lung cancer by inhibiting STAT3. Cell Physiol Biochem 44: 2017-2028, 2017.

8. Wang P, Chen D, Ma H and Li Y: LncRNA SNHG12 contributes to multidrug resistance through activating the MAPK/Slug pathway by sponging miR-181a in non-small cell lung cancer. Oncotarget 8: 84086-84101, 2017.

9. Wang P, Deng Y and Fu X: MiR-509-5p suppresses the proliferation, migration, and invasion of non-small cell lung cancer by targeting YWHAG. Biochem Biophys Res Commun 482: 935-941, 2017

10. Wang SY, Li Y, Jiang YS and Li RZ: Investigation of serum miR-411 as a diagnosis and prognosis biomarker for non-small cell lung cancer. Eur Rev Med Pharmacol Sci 21: 4092-4097, 2017.

11. Li J, Tan Q, Yan M, Liu L, Lin H, Zhao F, Bao G, Kong H, Ge C, Zhang F, et al: miRNA-200c inhibits invasion and metastasis of human non-small cell lung cancer by directly targeting ubiquitin specific peptidase 25. Mol Cancer 13: 166, 2014.
12. Meng F, Zhang L, Shao Y, Ma Q and Lv H: MicroRNA-377 inhibits non-small-cell lung cancer through targeting AEG-1. Int J Clin Exp Pathol 8: 13853-13863, 2015.

13. Weber DG, Brik A, Casjens S, Burek K, Lehnert M, Pesch B, Taeger D, Brüning T, Johnen G and MoMar study group: Are circulating microRNAs suitable for the early detection of malignant mesothelioma? Results from a nested case-control study. BMC Res Notes 12: 77, 2019.

14. do Amaral AE, Cisilotto J, Creczynski-Pasa TB and de Lucca Schiavon L: Circulating miRNAs in nontumoral liver diseases. Pharmacol Res 128: 274-287, 2018.

15. Wei J, Gao W, Zhu CJ, Liu YQ, Mei Z, Cheng T and Shu YQ: Identification of plasma microRNA-21 as a biomarker for early detection and chemosensitivity of non-small cell lung cancer. Chin J Cancer 30: 407-414, 2011.

16. Dinh TK, Fendler W, Chalubinska-Fendler J, Acharya SS, O'Leary C, Deraska PV, D'Andrea AD, Chowdhury D and Kozono D: Circulating miR-29a and miR-150 correlate with delivered dose during thoracic radiation therapy for non-small cell lung cancer. Radiat Oncol 11: 61, 2016.

17. Ye FG, Song CG, Cao ZG, Xia C, Chen DN, Chen L, Li S, Qiao F, Ling H, Yao L, et al: Cytidine deaminase axis modulated by miR-484 differentially regulates cell proliferation and chemoresistance in breast cancer. Cancer Res 75: 1504-1515, 2015.

18. Hu Y, Xie H, Liu Y, Liu W, Liu M and Tang H: miR-484 suppresses proliferation and epithelial-mesenchymal transition by targeting ZEB1 and SMAD2 in cervical cancer cells. Cancer Cell Int 17: 36, 2017.

19. Li T, Ding ZL, Zheng YL and Wang W: MiR-484 promotes non-small-cell lung cancer (NSCLC) progression through inhibiting Apaf-1 associated with the suppression of apoptosis. Biomed Pharmacother 96: 153-164, 2017.

20. Osmani L, Askin F, Gabrielson E and Li QK: Current WHO guidelines and the critical role of immunohistochemical markers in the subclassification of non-small cell lung carcinoma (NSCLC): Moving from targeted therapy to immunotherapy. Semin Cancer Biol 52: 103-109, 2018.

21. Ofori JK, Salunkhe VA, Bagge A, Vishnu N, Nagao M, Mulder H, Wollheim CB, Eliasson L and Esguerra JL: Elevated miR-130a/miR130b/miR-152 expression reduces intracellular ATP levels in the pancreatic beta cell. Sci Rep 7: 44986, 2017.

22. Livak KJ and Schmittgen TD: Analysis of relative gene expression data using real-time quantitative PCR and the 2(-Delta Delta C(T)) method. Methods 25: 402-408, 2001.

23. Wang T, Liu X, Tian Q, Liang T and Chang P: Increasing expression of miR-5100 in non-small-cell lung cancer and correlation with prognosis. Eur Rev Med Pharmacol Sci 21: 3592-3597, 2017.

24. Wang Y, Cong W, Wu G, Ju X, Li Z, Duan X, Wang X and Gao H: MiR-376a suppresses the proliferation and invasion of non-small-cell lung cancer by targeting c-Myc. Cell Biol Int 42: 25-33, 2018.

25. Wang Z, Liu Z, Fang X and Yang H: MiR-142-5p suppresses tumorigenesis by targeting PIK3CA in non-small cell lung cancer. Cell Physiol Biochem 43: 2505-2515, 2017.

26. Wei K, Pan C, Yao G, Liu B, Ma T, Xia Y, Jiang W, Chen L and Chen Y: MiR-106b-5p promotes proliferation and inhibits apoptosis by regulating BTG3 in non-small cell lung cancer. Cell Physiol Biochem 44: 1545-1558, 2017.

27. Yi R, Feng J, Yang S, Huang X, Liao Y, Hu Z and Luo M: miR-484/MAP2/c-Myc-positive regulatory loop in glioma promotes tumor-initiating properties through ERK1/2 signaling. J Mol Histol 49: 209-218, 2018.

28. Merhautova J, Hezova R, Poprach A, Kovarikova A, Radova L, Svoboda M, Vyzula R, Demlova R and Slaby O: miR-155 and miR-484 Are associated with time to progression in metastatic renal cell carcinoma treated with sunitinib. Biomed Res Int 2015: 941980, 2015

29. Halvorsen AR, Sandhu V, Sprauten M, Flote VG, Kure EH, Brustugun OT and Helland A: Circulating microRNAs associated with prolonged overall survival in lung cancer patients treated with nivolumab. Acta Oncol 57: 1225-1231, 2018.

30. Chen X, Hu Z, Wang W, Ba Y, Ma L, Zhang C, Wang C, Ren Z, Zhao Y, Wu S, et al: Identification of ten serum microRNAs from a genome-wide serum microRNA expression profile as novel noninvasive biomarkers for nonsmall cell lung cancer diagnosis. Int J Cancer 130: 1620-1628, 2012. 